University of Vermont

UVM ScholarWorks

Rubenstein School of Environment and Natural Rubenstein School of Environment and Natural Resources Faculty Publications

$7-1-2013$

\title{
Mapping the margin: Comparing marginal values of tropical forest remnants for pollination services
}

\author{
Taylor H. Ricketts \\ University of Vermont \\ Eric Lonsdorf \\ Urban Wildlife Institute
}

Follow this and additional works at: https://scholarworks.uvm.edu/rsfac

Part of the Agriculture Commons, and the Sustainability Commons

\section{Recommended Citation}

Ricketts TH, Lonsdorf E. Mapping the margin: comparing marginal values of tropical forest remnants for pollination services. Ecological Applications. 2013 Jul;23(5):1113-23.

This Article is brought to you for free and open access by the Rubenstein School of Environment and Natural Resources at UVM ScholarWorks. It has been accepted for inclusion in Rubenstein School of Environment and Natural Resources Faculty Publications by an authorized administrator of UVM ScholarWorks. For more information, please contact scholarworks@uvm.edu. 


\title{
Mapping the margin: comparing marginal values of tropical forest remnants for pollination services
}

\author{
TAyLor H. Ricketts ${ }^{1,4}$ AND ERic LonSDORF ${ }^{2,3}$ \\ ${ }^{1}$ Gund Institute for Ecological Economics, University of Vermont, Burlington, Vermont 05482 USA \\ ${ }^{2}$ Urban Wildlife Institute, Lincoln Park Zoo, Chicago, Illinois 60614 USA \\ ${ }^{3}$ Plant Conservation Science, Chicago Botanic Garden, Glencoe, Illinois 60022 USA
}

\begin{abstract}
Natural ecosystems benefit human communities by providing ecosystem services such as water purification and crop pollination. Mapping ecosystem service values has become popular, but most are static snapshots of average value. Estimating instead the economic impacts of specific ecosystem changes can better inform typical resource decisions. Here we develop an approach to mapping marginal values, those resulting from the next unit of ecosystem change, across landscapes. We demonstrate the approach with a recent model of crop pollination services in Costa Rica, simulating deforestation events to predict resulting marginal changes in pollination services to coffee farms. We find that marginal losses from deforestation vary from zero to US\$700/ha across the landscape. Financial risks for farmers from these losses and marginal benefits of forest restoration show similar spatial variation. Marginal values are concentrated in relatively few forest parcels not identified using average value. These parcels lack substitutes: nearby forest parcels that can supply services in the event of loss. Indeed, the marginal value of forest parcels declines exponentially with the density of surrounding forest cover. The approach we develop is applicable to any ecosystem service. Combined with information on costs, it can help target conservation or restoration efforts to optimize benefits to people and biodiversity.
\end{abstract}

Key words: agriculture; bees; coffee; Costa Rica; ecological economics; economic valuation; ecosystem services; land use change; landscape ecology.

\section{INTRODUCTION}

Natural ecosystems benefit human communities by providing many ecosystem services, including carbon storage, water regulation and purification, crop pollination, and recreational and spiritual opportunities (Kareiva et al. 2011). The substantial value of these ecosystem services can provide powerful motivation to protect ecosystems, based on economics and human welfare (Balmford et al. 2002). These arguments complement those traditionally based on intrinsic or non-utilitarian values of nature (Goulder and Kennedy 2011). Ecosystem services also have promise to generate sustainable funding for conservation through payments and markets (Salzman 2005, Pfaff et al. 2008, Wunder et al. 2008), which provide financial incentives to owners and users of natural ecosystems to conserve them rather than convert them to other uses.

Despite this potential, the specific ecological and economic dynamics of ecosystem services remain poorly understood (Kremen 2005). As a result, decision makers lack information on where ecosystem services come from, whom they benefit, and how much they are worth. To best inform typical conservation and natural

Manuscript received 21 September 2012; accepted 16 January 2013. Corresponding Editor: D. Brunton.

${ }^{4}$ E-mail: taylor.ricketts@uvm.edu resource decisions, this information must provide ecosystem service values across landscapes or regions, and quantify the consequences of change in land use or management (Daily 1997, Daily and Matson 2008, Kareiva et al. 2011).

An increasing number of studies have mapped ecosystem services across watersheds, regions, or landscapes. These studies show that the importance of ecosystem services can vary spatially by several fold (Naidoo et al. 2008, Nelson et al. 2009). Overall concordance among patterns of ecosystem services and biodiversity varies, but all landscapes contain at least some areas where conservation can secure high levels of both biodiversity and ecosystem services (Chan et al. 2006, Naidoo et al. 2008, Nelson et al. 2009, Egoh et al. 2011, Polasky et al. 2011). In a global example, Naidoo et al. (2008) map four ecosystem services and compare their distributions to those of range-restricted species. They find no overall concordance in spatial patterns, but identify areas of dual benefit and of trade-offs both among and within ecoregions.

Fewer studies quantify the consequences of landscape change on the sources and delivery of ecosystem services. Of those that do, most employ scenarios to evaluate the consequences of broad alternative futures (Richardson et al. 1996, Carpenter et al. 2006, Priess et al. 2007, Nelson et al. 2009). A more flexible approach to examining change involves calculating marginal values 
(e.g., Turner et al. 2003, Dutton et al. 2010, Turner et al. 2010). Here we define marginal values in the practical applied sense, as the value of a unit change in a landscape (Turner et al. 1993). Our definition is thus a discretized approximation of formal marginal values associated with infinitesimal change. Calculated across all landscape units, marginal values indicate where, for example, the next increment of habitat destruction (or restoration) would be most costly (or beneficial) for ecosystem services.

Marginal values are typically more relevant to land and resource decisions than static estimates of current value (hereafter, "average value"). Most decisions involve marginal changes to a landscape or resource pool (e.g., converting a given forest parcel to agriculture). Because changes are small relative to overall markets or values, valuation is simpler than larger changes that may affect market dynamics or consumer behavior (Turner et al. 2003). Furthermore, marginal values support more sophisticated and complete analyses of ecosystem change, including landscape optimization, dynamic conservation planning, and return on investment (Polasky et al. 2011).

Here we develop a spatially explicit approach to analyzing marginal values, and we demonstrate it using crop pollination as an example. Pollination by bees and other animals is important for production of $70 \%$ of major food crops, representing 3-8\% of global agricultural production (Klein et al. 2007, Aizen et al. 2009). While managed honey bees (Apis mellifera) are employed for many crops, wild bees are efficient pollinators of many crops (Free 1993), and the importance of conserving them within agricultural landscapes is increasingly recognized (Klein et al. 2007, Lonsdorf et al. 2011). Although the value of wild pollinators to crops is a topic of debate (Ghazoul 2005, Steffan-Dewenter et al. 2005), empirical studies have shown that pollinator activity often declines with increasing isolation from natural or seminatural habitats (Ricketts et al. 2008, Garibaldi et al. 2011) and this decline can affect crop yield (Kremen et al. 2002, Klein et al. 2003, Ricketts et al. 2004).

Our analyses employ a recent model that predicts delivery of pollination services across agricultural landscapes (Lonsdorf et al. 2009, 2011). The model uses relatively simple data on land cover, resource distributions, pollinator foraging distances, and yield responses to estimate the distribution of pollination services and the resulting values of pollinator source habitats. We apply this spatially explicit model in a coffee-producing landscape in Costa Rica. We simulate marginal changes in forest cover, predict resulting changes in pollination services, and ask three central questions about marginal values: (1) Where would forest loss result in the largest change in pollination services in this landscape? (2) Which specific coffee farms are likely to lose most pollination services due to forest loss? (3) Where would restoration most enhance pollination services to coffee farms?

In principle, any decision regarding the use of land and resources should rest on a careful comparison of marginal costs and benefits. In this paper, we focus on a novel approach to estimate one side of this comparison: the marginal benefits of conserving forest for crop pollination. The other side, the costs of conserving those forests, is beyond the scope of this paper. Combining information on the costs and benefits of conservation can help estimate net benefits, guide resource decisions, and target payments for ecosystem services (Naidoo et al. 2006, Naidoo and Ricketts 2006, Balmford et al. 2011).

\section{Methods \\ Landscape}

We focus on a Costa Rican agricultural landscape composed of coffee farms, sugar cane fields, and cattle pastures, all surrounding tropical forest remnants ranging in size from two to hundreds of hectares. To create a land cover/land use map of the landscape, we classify $1-\mathrm{m}$ resolution aerial photographs (circa. 2000) into seven broad land cover classes, using supervised object-based classification in ENVI software (Excelis Visual Information Systems, Boulder, Colorado, USA; Fig. 1). We then resample the image to $30-\mathrm{m}$ cells (hereafter, "parcels"), and assign each parcel the land cover class corresponding to the majority of its 1-m pixels.

In this landscape, Ricketts (2004) sampled pollinator activity on coffee flowers in 12 sites within a large complex of coffee farms (Fig. 1) and found that pollinator richness, visitation rate, and pollen deposition rates all decline significantly with increasing distance from natural forest. Using pollen limitation experiments in these same sites, Ricketts et al. (2004) showed that coffee yields also declined with isolation from forests, with coffee plants within $1 \mathrm{~km}$ from forest yielding an average of $18 \%$ higher than plants further away. We used these findings to parameterize and to calibrate our model. Results from Ricketts (2004) also suggest that forest patches smaller than 20 ha provide few pollinators to surrounding coffee. We therefore modify the land cover map to distinguish between forest $(>20$-ha patch size) and small forest ( $<20$-ha patch size). We focus our analyses of marginal value on changes in the forest class only.

\section{Model}

To estimate the marginal value of forest parcels, we use a model of pollination services that has previously been developed and fit to this landscape (Lonsdorf et al. 2009, 2011). The model is intended to support management decisions in data-poor regions (Kareiva et al. 2011), so it is simple. We use it here to demonstrate our approach to estimating marginal values. The model performs four steps to estimate the agricultural produc- 


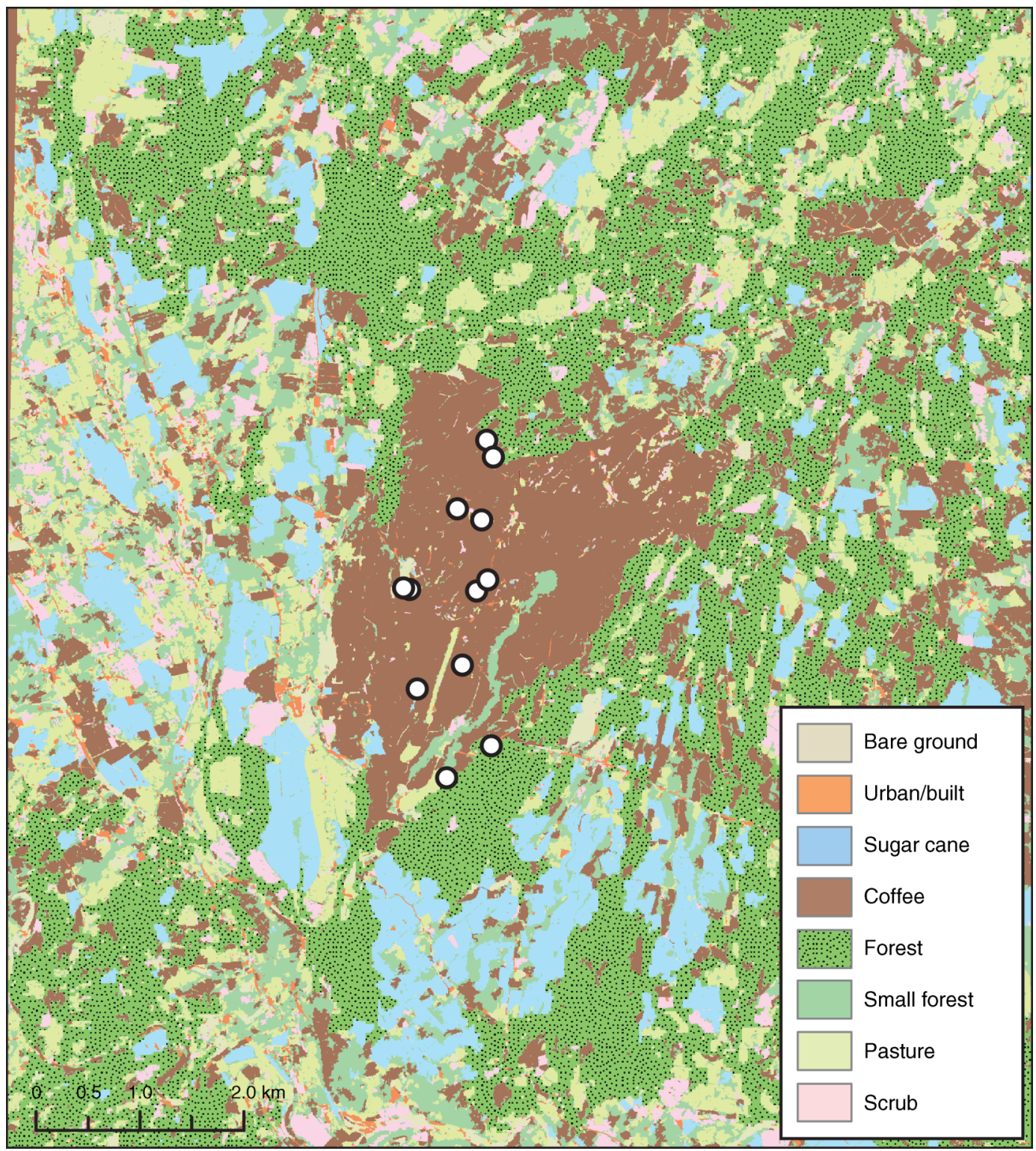

FIG. 1. Land use/land cover map of study landscape in Costa Rica. The 12 circles locate field samples of bee abundance and pollen limitation used to validate the model. Note that forests are divided into two classes, representing patches $>20$ ha (forest) and patches $<20$ ha (small forest).

tion on a parcel of coffee as a function of the surrounding land cover. Because the basic model has been published before, we describe steps 1 and 2 only briefly (see Lonsdorf et al. [2009, 2011] and the Appendix for more detail).

First, the model provides a pollinator supply score in each parcel. To calculate the supply, the model assumes that pollinators require nesting substrates and floral resources to persist on a landscape and that the suitability of each land cover type to provide these resources vary. Thus the supply of pollinators at a nest site depends on the quality of the nest and the floral resources surrounding it, and the model assumes that nearby resources contribute more than those farther away.

Second, we use the results of step 1 to estimate the abundance of pollinators visiting each coffee parcel, again assuming the supply from nearby parcels contribute more than those farther away. The model produces a relative index $(0-1)$ of pollinator abundance.

We then calibrate this abundance index, $\hat{P}_{o}$, to estimate actual abundance of pollinators on farm $o$, $P_{o}$, by fitting model output with empirical data (Ricketts 2004). We choose a slightly modified Type III functional response for this purpose, to avoid non-defined zero values and to allow saturation at 108 pollinator visitors, 

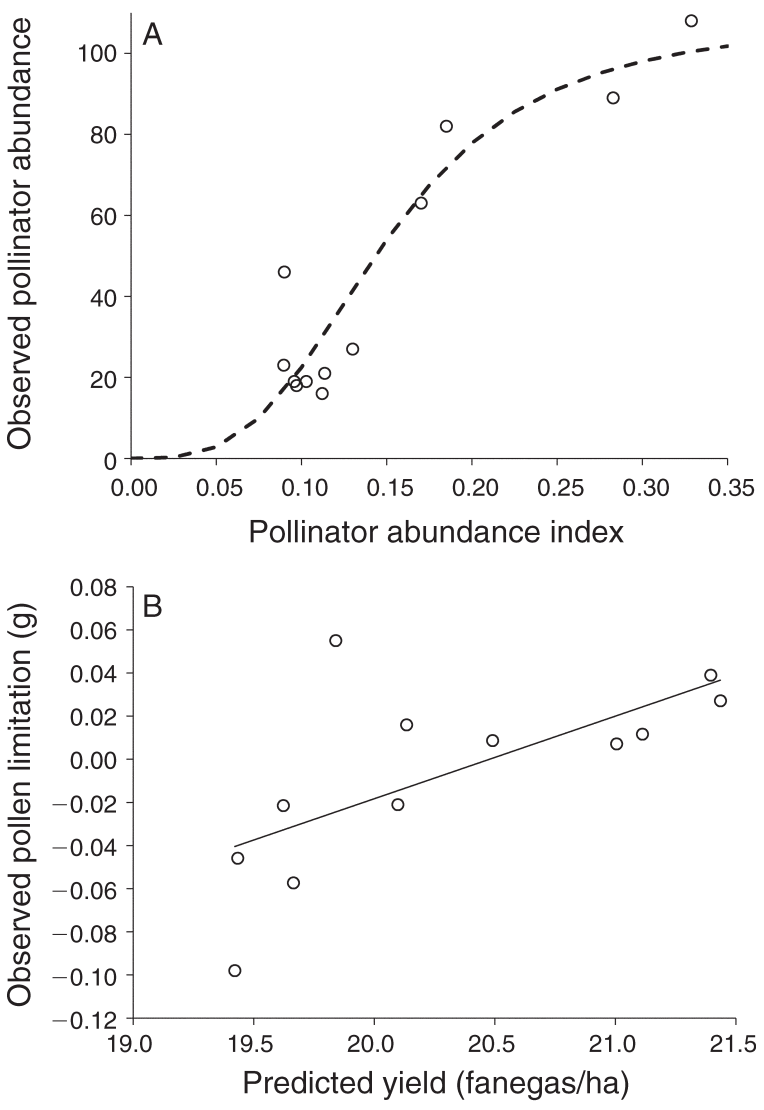

FIG. 2. Validating model predictions with field observations and experiments. (A) Relationship between model abundance index and observed pollinator abundances in coffee sites. The curve is a modified type III saturating function (see Eq. $1 ; R^{2}=$ $0.866, P<0.001$ ). (B) Relationship between model predictions of coffee yield and results of pollen limitation experiments in the field (yield per fruit from open pollination minus yield per fruit from hand pollination; $y=0.038 x-0.784 ; R^{2}=0.440, P=$ $0.019)$. 1 fanega $=200 \mathrm{~L}$ coffee berries.

the maximum recorded in field studies (Ricketts 2004). The resulting function is

$$
P_{o}=108 \frac{\hat{P}_{o}^{\gamma}}{\tau^{\gamma}+\hat{P}_{o}^{\gamma}}
$$

where $\tau$ is the half-saturating constant (the index value yielding a predicted abundance of 54) and $\gamma$ is a constant that determines the shape of the saturating (i.e., increasing $\gamma$ leads to a more step-like function). Using the empirical data for $P_{o}$ and model predictions for $\hat{P}_{o}$, we used Monte Carlo parameterization to determine the values of half-saturation constant $\kappa$ and $\gamma$ that maximized the fit (0.153 and 3.298, respectively; Fig. 2A).

Third, we use a simple saturating yield function to translate the abundance of pollinators on farms into an expected yield (Lonsdorf et al. 2011). Yield can increase as pollinator abundance increases (Greenleaf and Kremen 2006), but crops vary in their dependence on pollinators. We thus calculate the expected yield of a crop $c$ on farm $o, Y_{o}$, as

$$
Y_{o}=Y_{\max }\left(1-v_{c}+v_{c} \frac{P_{o}}{P_{o}+\kappa_{c}}\right)
$$

where $Y_{\max }$ is the maximum crop yield, $v_{c}$ represents the proportion of crop c's yield attributed only to wild pollination (e.g., $v_{c}$ would be equal to 1 if a crop is an obligately outcrossing species and equal to 0 if the crop species were wind pollinated). In the denominator of the third term, $\kappa_{c}$ is a half-saturation constant and represents the abundance of pollinators required to reach $50 \%$ of pollinator-dependent yield.

We use field results from Ricketts et al. (2004) to estimate yield parameters. The maximum yield of coffee is approximately 21.5 fanegas per hectare ( 1 fanega $=$ 200 liters of berries). Ricketts et al. (2004) observed that yield declined $18 \%$ between areas with abundant bee visits and areas with fewest bee visits, so we set $v_{c}$ to 0.18 . To fit the saturating function to the maximum abundance observed in the field (i.e., 108 total visiting bees) we set $\kappa_{c}$ to 30 and multiplied the saturating function by a scalar equal to 1.27. Thus the yield function for this work is

$$
Y_{o}=21.5\left(0.82+0.18 \frac{1.27 P_{o}}{P_{o}+30}\right) .
$$

The monetary value of the crop on farm $o, V_{o}$, is simply the product of yield per hectare, $Y_{o}$, crop area, and net revenue (price minus variable costs) per unit crop sold. Net revenue was approximately US\$35 per fanega during the time of the original Ricketts et al. (2004) study; we adjusted this estimate to US $\$ 48$ per fanega in 2011 dollars (assuming a 3\% inflation rate).

Predicted coffee yields $\left(Y_{o}\right)$ relate well to results of independent field tests of pollen limitation (Fig. 2B), experimentally measured by Ricketts et al. (2004). This relationship suggests that the model is predicting areas where pollination services by wild bees are most benefiting coffee yields.

Fourth, we distribute crop values attributable to pollinators back onto the landscape to estimate the value of each parcel to surrounding coffee farms. In model step 2 (Appendix: Eq. A.3) we estimated pollinator abundance on farm $o$ by summing the proportion of pollinators foraging from all $X$ parcels to farm $o$. Here, we apportion value from coffee parcels back to all nearby parcels, according to these same proportional abundances. Thus, parcels close to crops are assigned a greater proportion of value than parcels further away. Formally, we calculate pollinator service provided to $O$ farms from each parcel $x, \mathrm{PS}_{x}$, as

$$
\mathrm{PS}_{x}=v_{c} \sum_{o=1}^{O} V_{o} \frac{P_{o x}}{\hat{P}_{o}}
$$

where $V_{o}$ represents the crop value in parcel $o$. This is the "average value" of each parcel in providing crop 
pollination services (see introduction), as opposed to the marginal value we estimate next.

\section{Marginal value, vulnerability, and restoration}

Our basic approach is to simulate marginal losses of forest across the landscape and then quantify resulting changes in pollination services to coffee. We generally consider deforestation events of $3 \times 3$ blocks of $30-\mathrm{m}$ parcels, totaling 0.81 ha (blocks were not allowed to overlap). The choice of this size is arbitrary, but it is a common increment of land use change in the region (T. H. Ricketts, personal observation). For each such block in turn, we simulate conversion to pasture of all forest parcels within it (parcels classified as small forest were not altered; see Methods: Landscape). We choose pasture as the fate of all deforested parcels as a simple extreme case, since pasture neither supports nor benefits from wild pollinators.

Marginal value.-We define marginal value here as the change in coffee production value per hectare of deforested land. To determine marginal values of forest pixels within block $x$, we use the model to calculate the difference in total coffee production on the landscape resulting from the deforestation of all forest parcels in $x$. The marginal value of block $x, \mathrm{MV}_{x}$, is thus

$$
\mathrm{MV}_{x}=\sum_{o=1}^{O} V_{o}(x=\text { current })-\sum_{o=1}^{O} V_{o}(x=\text { deforested })
$$

where $V_{o}$ is the value of coffee on parcel $o$ and thus the sum over all $O$ parcels represents the total value of coffee on the landscape. It follows that if there is no forest present within block $x$ of the base landscape, its marginal value is 0 . We then distribute block $x$ 's marginal value spatially to the forest parcels within it, in proportion to their pollinator supply scores (model step 1). Finally, we divide parcel values by their area to normalize values to US\$/ha.

Distribution of risk. - We use the marginal analysis to map the relative production risk among coffee parcels due to forest loss. We define risk here as the loss of coffee production on each coffee parcel given the deforestation of each $3 \times 3$ block. We report the maximum loss here as our measure of risk for each coffee parcel, although mean loss and other measures may also be appropriate. Formally, we calculate risk $\omega_{o}$, as the maximum percent change (loss) in coffee production value on coffee parcel $o$ due to conversion of forest to pasture in any block $x$, such that

$$
\omega_{o}=\max \left[\Delta V_{o}\left|\Delta x_{1}, \Delta V_{o}\right| \Delta x_{2}, \ldots, \Delta V_{o} \mid \Delta x_{n}\right]
$$

where $\Delta V_{o} \mid \Delta x_{1}$ represents the first of $n$ possible changes in value on coffee parcel $o$ given the change in land cover on the parcels in block $x_{1}$ from forest to pasture.

Restoration value.-We reverse the logic used in our marginal value analysis to calculate the restoration value of all non-forest parcels in the landscape. As with marginal value, we consider blocks of parcels at a time. We convert all non-forest parcels in the block to forest and compute the resulting change in the landscape's total value for coffee production. For these analyses, we use $9 \times 9$ parcel blocks (instead of $3 \times 3$ ) to reduce computation time. The potential restoration value of block $x, \mathrm{RV}_{x}$, is thus

$$
\mathrm{RV}_{x}=\sum_{o=1}^{O} V_{o} \mid(x=\text { restored })-\sum_{o=1}^{O} V_{o} \mid(x=\text { current })
$$

It follows that, if there is only forest present within block $x$ of the base landscape, its restoration value is 0 . As with marginal values, we distribute block $x$ 's restoration value spatially to the agricultural parcels within it, and normalize values to US\$/ha.

We implement all models and simulations in MATLAB (MathWorks, Natick, Massachusetts, USA).

\section{Results}

Our model predicts a highly heterogeneous pattern of crop pollination services across the landscape (Fig. 3). As expected, coffee fields near the forest land cover class are predicted to receive a high abundance of wild pollinators (Fig. 3A). Also intuitive, forested areas that are large and near to coffee fields are predicted to provide the highest average value for pollination services, in terms of annual contribution to yields in surrounding coffee fields (Fig. 3B). Note that coffee fields are predicted to be significant sources of pollination value to themselves, because they support some bee abundance.

With the model in place and some encouraging validation (see Methods; Fig. 2), we address our questions of marginal value by destroying forest parcels in turn and estimating the resulting changes in coffee production. We find marginal values that range from US\$0 to US\$700 per hectare per year (Fig. 4), and a spatial distribution that is different in important ways from that of average value. Highest marginal values are found in forests that provide high-quality resources for bees, are near to large areas of coffee, and, crucially, for which there are few substitutes (i.e., other nearby forest areas to supply pollinators). Indeed, the average marginal value of forest parcels declines exponentially with forest cover within a 500-m radius (Fig. 5).

There is a strong overall relationship between average and marginal value (Fig. 6), although there is significant scatter. In particular, the highly positive residuals indicate that many forest parcels have much higher marginal values than one would expect given their average value. These are the parcels with few substitutes: if they are lost, few other forest parcels exist to supply pollinators to nearby coffee fields. Also of interest in Fig. 6 is that most points lie below the 1:1 line. For most parcels, our estimate of average value is greater than our estimate of marginal value. 

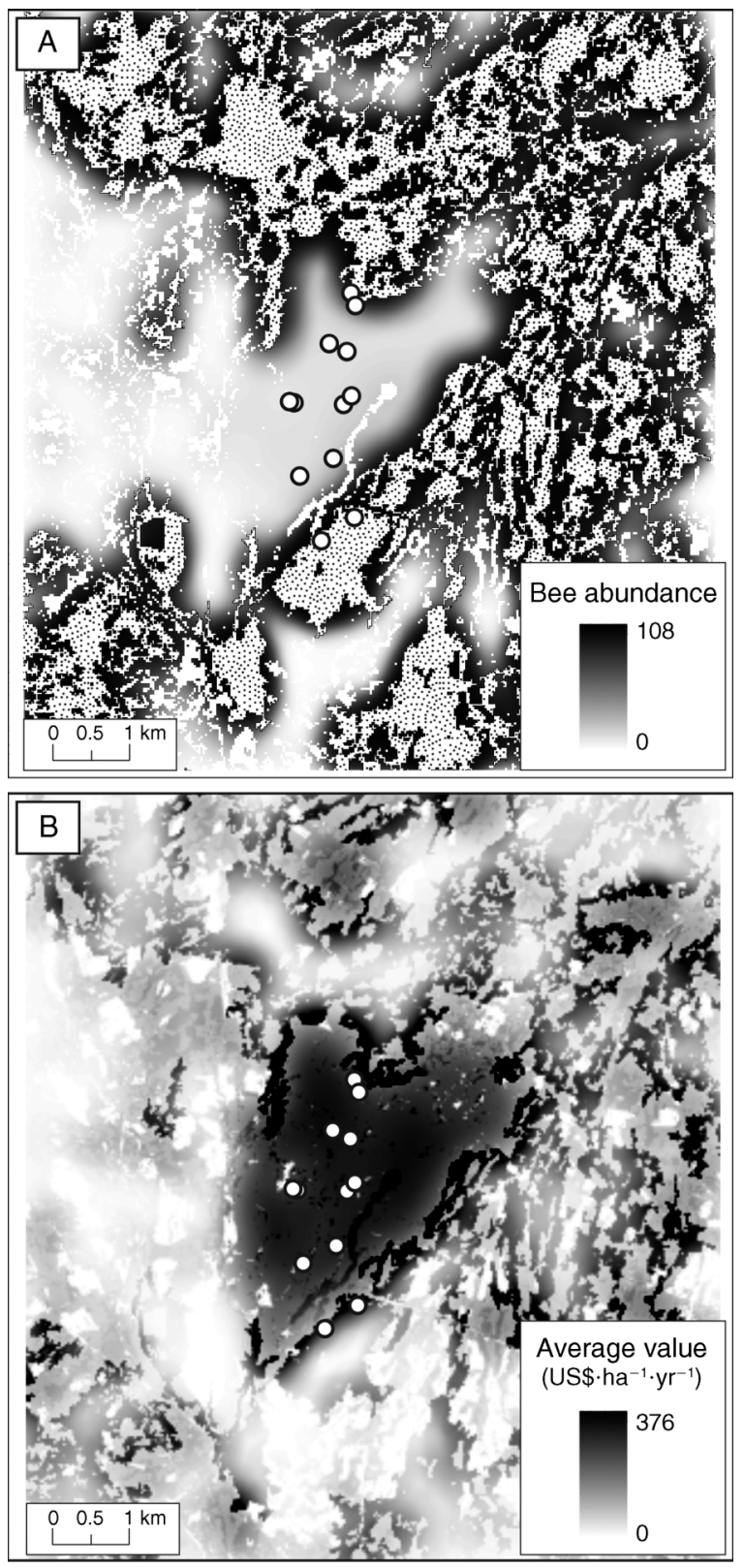

FIG. 3. Simple results of the crop pollination model on our study landscape in Costa Rica. (A) Predicted abundance of wild pollinators on each agricultural parcel in the landscape (total abundance of visitors). Forest patches $>20$ ha are stippled for reference. White areas correspond to forest patches $<20$ ha in area, which were not considered in these analyses. (B) Predicted average value of pollination services to coffee crops from each parcel in the landscape.

The relative risks to coffee farmers from deforestation also vary among agricultural parcels. Maximum percentage losses range from $0 \%$ to $1.9 \%$ given our simulated deforestation events of 0.81 ha at a time (Fig. 7). In general, farmers close to high-quality forests with few substitutes are expected to lose most productivity from marginal reductions in forest cover. In other words, farmers close to forests of high marginal value face the most risk from deforestation. The magnitude of losses we report are sensitive to the size of the changes we simulate (see Discussion). Larger events would produce a higher percentage of losses for farmers.

The model predicts marginal benefits of a unit of forest restoration that range from US\$0 to US\$1325 per hectare of restored forest (Fig. 7). Highest values tend to be found in areas that have substantial amounts of coffee nearby and that are far from existing areas of forest. Indeed, forest restoration within large coffee farms is predicted to result in the highest marginal benefits. Clearly, restoration will not immediately confer pollination benefits. Forest regeneration takes decades, and key habitat features such as nesting sites and floral resources may only develop over time. For example, social meliponine bees are important coffee pollinators in this system and utilize cavities in mature trees as nest sites (Ricketts 2004).

\section{DisCuSSION}

We develop a general approach to estimate gross marginal values of ecosystem services across landscapes, and we demonstrate it using a simple model to predict changes in crop pollination services from changes in tropical forest cover. We show that marginal losses from deforestation (Fig. 4), financial risks for coffee farmers from these losses (Fig. 7), and marginal benefits of forest restoration (Fig. 8) all vary across the landscape. In

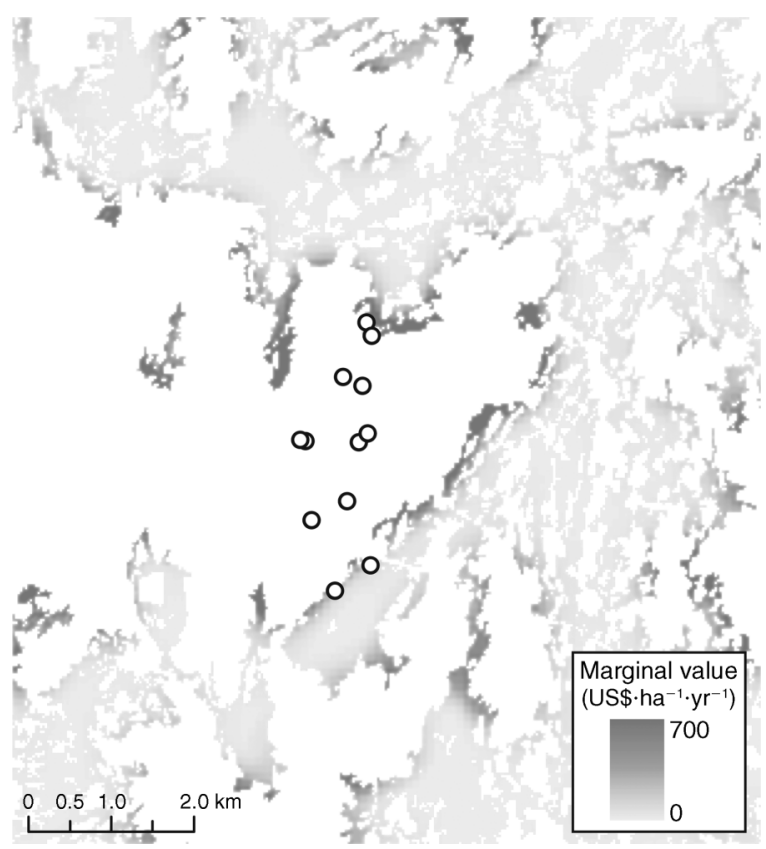

FIG. 4. Marginal values of all forest parcels for pollination services. The map displays the predicted change in coffee production value in the landscape, given the simulated deforestation of each 0.81 -ha $(3 \times 3$ parcel $)$ block. White areas correspond to agricultural lands or forest patches $<20$ ha in area. 


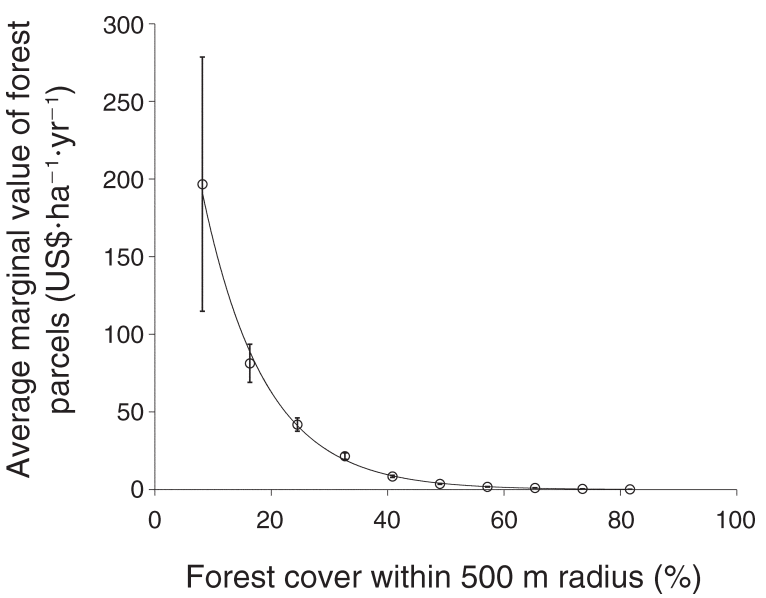

FIG. 5. Influence of surrounding forest cover on marginal values. Marginal values decline exponentially with increasing forest cover within a $500-\mathrm{m}$ radius $\left(y=412.38 e^{-9.407} x, R^{2}=\right.$ $0.998)$. Ten levels were chosen uniformly from the continuous range of percent forest cover, and average marginal value calculated across all forest parcels with that level of surrounding forest cover. Error bars represent 95\% confidence limits.

particular, marginal values are concentrated in a few forest parcels that are not identified using average value approaches. Therefore, many forest parcels credited with supplying significant ecosystem services are not those for which destruction would result in largest change in benefit. Marginal values allow us to anticipate likely consequences of ongoing land use change on ecosystem services and the local communities that depend on them.

Why do average and marginal values differ? The answer involves saturation and substitutes. In areas of abundant forest, the supply of pollinators is saturated: there is more than enough forest to provide adequate pollination services to nearby coffee fields. Forest parcels may hold high average value, but the loss of any one of them would be compensated by other parcels, so marginal value is low. Conversely, in areas with abundant coffee but few forest parcels, pollinator supply is likely not saturated. There are few substitutes; deforestation would remove perhaps the only source of nearby pollination services.

Because of this saturation effect, marginal values are highly sensitive to the amount of nearby forest cover (Fig. 5). As deforestation progresses, forest parcels will tend to have fewer substitutes (i.e., they will move to the left in Fig. 5), and the marginal values of remaining forests will tend to rise. This also illustrates an important general point: our results depict only the consequences of the next unit of deforestation. Each deforestation event will update the marginal values of remaining forests, requiring re-mapping of marginal values at each time step. Analyzing time series of changes and their relative values is an area that warrants further research.
Marginal values are also likely to be sensitive to the scale of change considered. We simulated relatively small deforestation events (typically $0.81 \mathrm{ha}$ ). The spatial pattern of marginal values is unlikely to change substantially with modest increases in the size of deforestation events. As these events become large relative to the typical foraging distances of coffee pollinators, however, we would expect larger absolute changes in pollination services, and a more homogeneous pattern of marginal values. In general, the effects on marginal values of the scale of change (relative to the spatial dynamics of the service itself) is an important area of future research.

Our analyses reinforce the need to consider both the supply and demand sides of ecosystem services when estimating their values. By definition, an ecosystem service is an ecosystem process that results in a benefit to people (Millennium Ecosystem Assessment 2005). Without users or beneficiaries, the value of any ecosystem service is zero (Tallis et al. 2008, Turner et al. 2010, Balmford et al. 2011). In this case, forest parcels with high average values for pollination services are not simply those that support large populations of pollinators. High values are instead found in such forests that are sufficiently near to large areas of coffee (Fig. 3B). Similarly, marginal values are highest for quality forest parcels surrounded by many service users (i.e., coffee farmers) who have few substitutes in case that parcel is destroyed (Fig. 4).

Our goal in this paper is to demonstrate an approach to estimating and interpreting marginal values of ecosystem services across landscapes. We therefore use a simple model, developed previously and fitted with simple data, to illustrate this approach. More robust spatial predictions of pollination services across agricultural landscapes would require a spatially explicit regression model to estimate parameters and evaluate

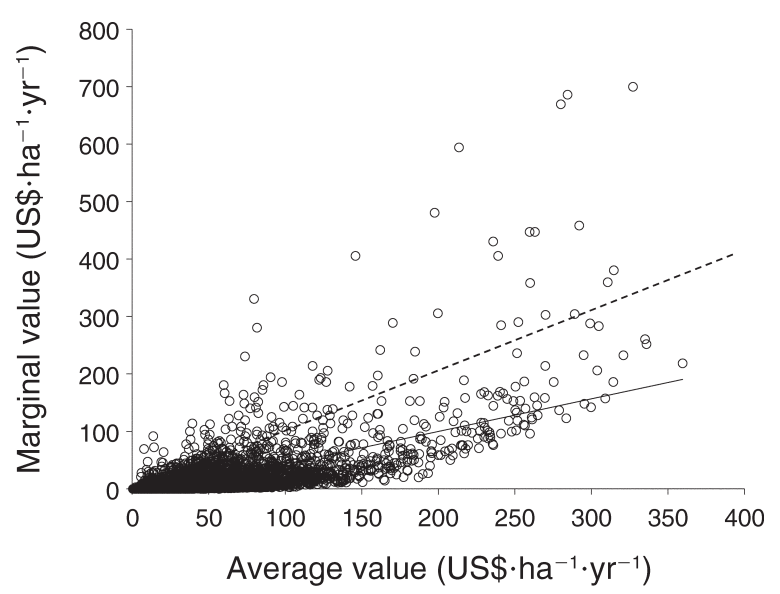

FIG. 6. Comparison between average and marginal values. The solid line indicates a simple linear regression $(y=0.568 x-$ $13.857 ; R^{2}=0.430$ ), and the dashed line indicates a $1: 1$ relationship. Each point represents the mean value of forest parcels within each 0.81 -ha $(3 \times 3$ parcel $)$ block. 


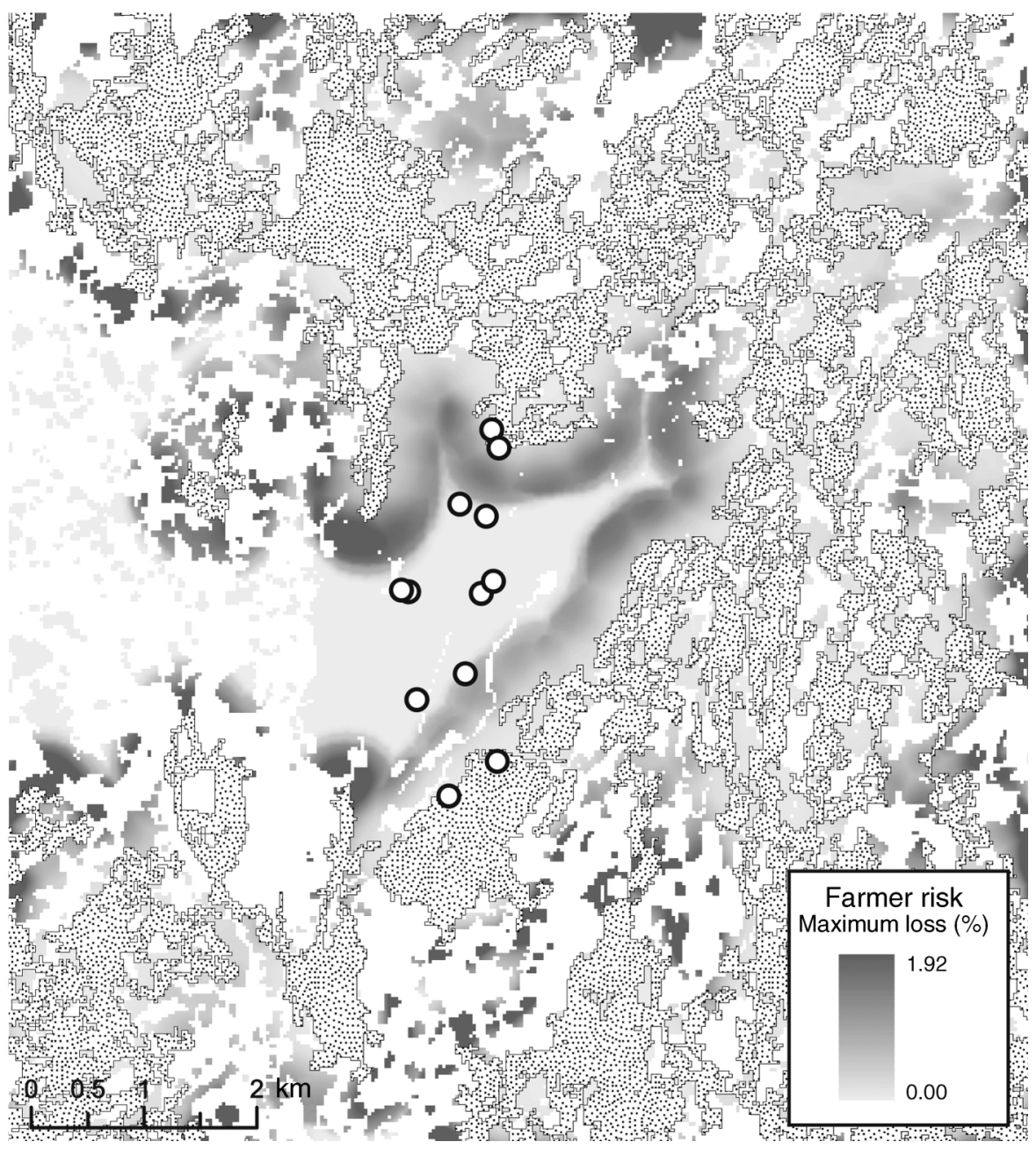

FIG. 7. Risk to coffee farmers from marginal changes in pollination services due to deforestation. The map displays the maximum percentage change in coffee production from all simulated deforestation events $(0.81$ ha $[3 \times 3$ parcel block] at a time $)$. Forest patches are stippled for reference. All other land classes besides coffee are left white.

predictive power. We have been conducting these analyses on $>20$ landscapes where field observations of pollination services also exist (Kennedy et al. 2013). Here, we instead use existing, published data and make several assumptions to simplify both the model structure and the simulations of forest loss. Model assumptions and simplifications are discussed in detail in previous papers (Lonsdorf et al. 2009, 2011), but three warrant mention here. First, our yield function models only the contribution of pollination to crop yield, and therefore assumes that no other resources (e.g., water, nitrogen) are limiting. In this landscape, abundant rainfall, applications of fertilizer, and field data (Ricketts et al. 2004) suggest that this is a reasonable assumption. Second, other than distinguishing forest from small forest land cover classes, we do not recognize minimum patch sizes in our analyses, to constrain computation time. Finally, we do not report uncertainty or model sensitivity here, to simplify our demonstration of the marginal value approach. Uncertainty and sensitivity are addressed in earlier papers (Lonsdorf et al. 2009, 2011).

Beyond improvements to the pollination model itself, a complete analysis of marginal ecosystem service values require at least three additional components not included here. The first is inclusion of multiple ecosystem services. Land use change typically affects a variety of benefit flows to people, as well as biodiversity itself. As a result, trade-offs among these benefits are critical to evaluate, but are rarely considered fully (Naidoo et al. 2008, Nelson et al. 2009, Egoh et al. 2011). The second is a treatment of costs. Land use decisions are ideally based on a careful comparison of benefits and costs. Like ecosystem service values, costs can vary substantially across landscapes and include management costs (e.g., maintaining boundaries, eradicating invasives) and opportunity costs (e.g., the forgone income from agriculture or other alternative 


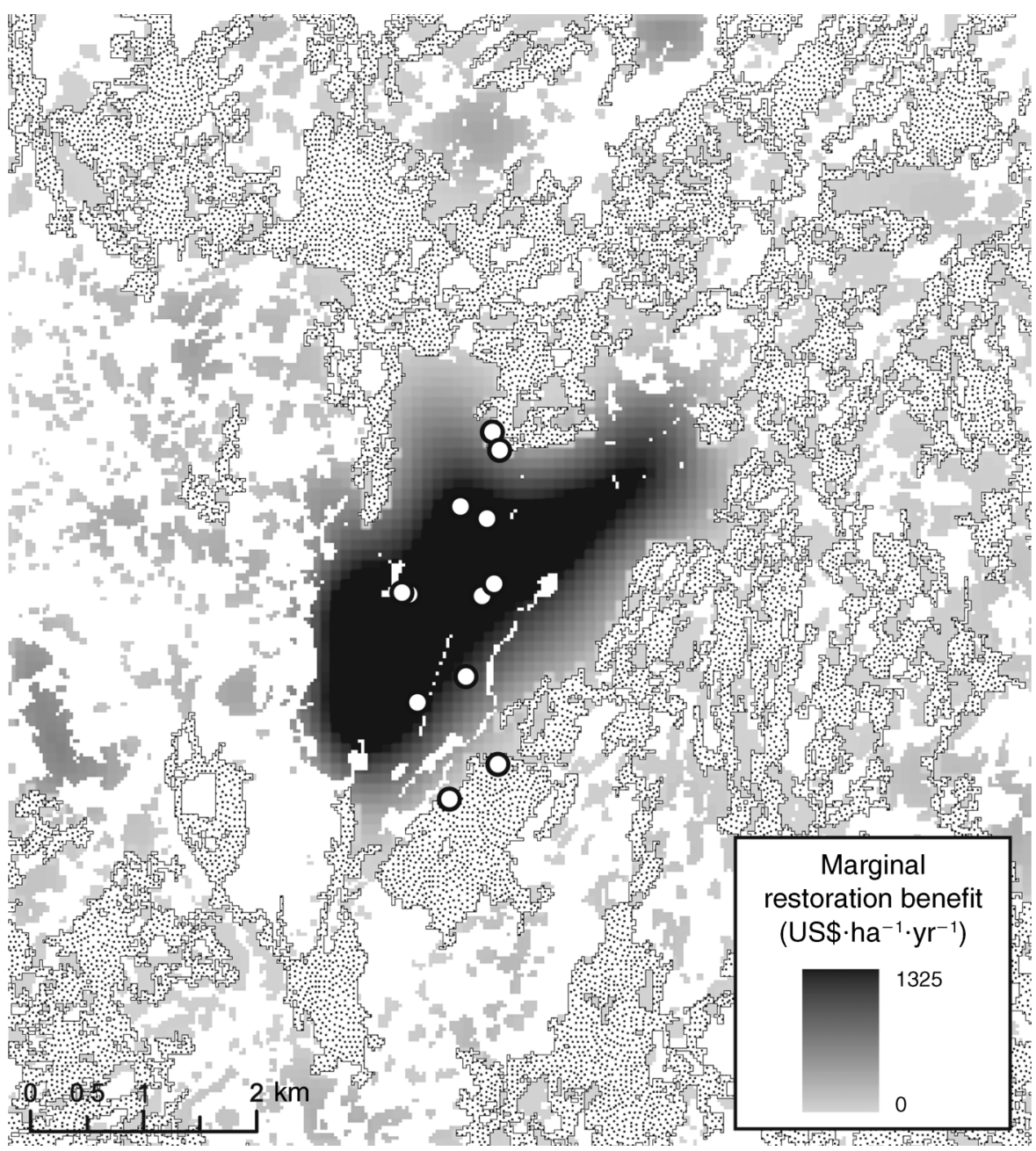

FIG. 8. Marginal benefits of forest restoration for pollination services. The map displays predicted change in coffee production value in the landscape, given simulated reforestation of each 7.3-ha $(9 \times 9$ parcel $)$ block. The more pixelated appearance of this figure, compared to Figs. 4 and 7, is due to these larger blocks (see Methods). Forest patches $>20$ ha are stippled for reference. All other land classes besides coffee are left white.

uses) (Naidoo et al. 2006, Balmford et al. 2011). Mapping costs will help target conservation investments toward areas where benefits far outweigh costs (i.e., high net benefit), and away from areas where the reverse is true (Naidoo et al. 2006). The third issue is the distribution of costs and benefits among the many farmers in typical landscapes. A landowner who converts a hectare of forest to pasture might lose some coffee pollination benefits but will gain some grazing income. His coffee-growing neighbors, however, may lose productivity with no benefit from grazing. This coordination problem is among the most difficult issues to overcome in the search for sustainable agricultural policies (Ostrom 2000).

A marginal approach to valuation can inform sophisticated analyses to support conservation decisions. First, optimization techniques are popular in helping to set biodiversity priorities (Margules and Pressey 2000). Parcel-level information on marginal benefits and costs can be readily incorporated into these techniques to optimize over both biodiversity and ecosystem services. Second, many authors have adopted a long-standing economic principle of return on investment: quantifying the biodiversity return for each alternative investment in conservation (Wilson et al. 2006, Murdoch et al. 2007). Marginal values provide rigorous estimates of the cost-effectiveness of conservation investments in terms of ecosystem services, broadening these approaches to include human benefits. Finally, spatially explicit marginal values can inform private decisions by landowners and their neighbors. By comparing economic impacts of a land use change among parcels, landowners can make more informed decisions on their own properties, and even negotiate payments among themselves for impacts that extend beyond them (Daily et al. 2009).

While we focus here on pollination services, this marginal approach to mapping values is applicable to 
any ecosystem service. It is especially useful for services such as water purification and provision of wild foods, where spatial dynamics make substitutes and saturation effects important. Mapping the marginal benefits of conserving these ecosystem services can clarify the impacts of ongoing land use change on the incomes and well-being of individuals and communities. Combined with information on marginal costs, this approach can also provide information necessary to operationalize ecosystem services within the resource decisions made daily by governments, corporations, and private landowners (Daily and Matson 2008).

\section{ACKNOWLEDGMENTS}

C. Kremen, N. Williams, and R. Winfree co-developed the landscape pollination model. Berry Brosi and Jaime Florez helped parameterize the model by providing expert opinion on habitat quality, and by measuring bee specimens to estimate flight ranges, respectively. Gregg Verutes created all maps. Thanks to B. Fisher, R. Naidoo, S. Polasky, H. Tallis, WWF's Conservation Science Program, UVM's Gund Institute, and anonymous reviewers for comments and suggestions that improved the manuscript. We are grateful for financial support from National Science Foundation (DEB-0918371), NSF's National Center for Ecological Analysis and Synthesis (Working Group on Pollination Services led by C. Kremen and N. Williams; DEB-0553768), The Google, Inc. fund of the Tides Foundation, and the Summit Foundation.

\section{Literature Cited}

Aizen, M. A., L. A. Garibaldi, S. A. Cunningham, and A. M. Klein. 2009. How much does agriculture depend on pollinators? Lessons from long-term trends in crop production. Annals of Botany 103:1579-1588.

Balmford, A., et al. 2002. Economic reasons for conserving wild nature. Science 297:950-953.

Balmford, A., B. Fisher, R. E. Green, R. Naidoo, B. Strassburg, R. K. Turner, and A. S. L. Rodrigues. 2011. Bringing ecosystem services into the real world: an operational framework for assessing the economic consequences of losing wild nature. Environmental and Resource Economics 48:161-175.

Carpenter, S. R., E. M. Bennett, and G. D. Peterson. 2006. Special feature on scenarios for ecosystem services. Ecology and Society 11(2):32.

Chan, K. M. A., M. R. Shaw, D. R. Cameron, E. C. Underwood, and G. C. Daily. 2006. Conservation planning for ecosystem services. PLoS Biology 4:2138-2152.

Daily, G. C., editor. 1997. Nature's services. Island Press, Washington, D.C., USA.

Daily, G. C., and P. A. Matson. 2008. Ecosystem services: from theory to implementation. Proceedings of the National Academy of Sciences USA 105:9455-9456.

Daily, G. C., S. Polasky, J. Goldstein, P. M. Kareiva, H. A. Mooney, L. Pejchar, T. H. Ricketts, J. Salzman, and R. Shallenberger. 2009. Ecosystem services in decision making: time to deliver. Frontiers in Ecology and the Environment 7:21-28.

Dutton, A., G. Edwards-Jones, and D. W. Macdonald. 2010. Estimating the value of non-use benefits from small changes in the provision of ecosystem services. Conservation Biology 24:1479-1487.

Egoh, B. N., B. Reyers, M. Rouget, and D. M. Richardson. 2011. Identifying priority areas for ecosystem service management in South African grasslands. Journal of Environmental Management 92:1642-1650.

Free, J. B. 1993. Insect pollination of crops. Second edition. Academic Press, London, UK.
Garibaldi, L. A., et al. 2011. Stability of pollination services decreases with isolation from natural areas despite honey bee visits. Ecology Letters 14:1062-1072.

Ghazoul, J. 2005. Buzziness as usual? Questioning the global pollination crisis. Trends in Ecology and Evolution 20:367373.

Goulder, L. H., and D. Kennedy. 2011. Interpreting and estimating the value of ecosystem services. Pages 23-47 in P. Kareiva, H. Tallis, T. H. Ricketts, G. C. Daily, and S. Polasky, editors. Natural Capital: Theory and practice of mapping ecosystem services. Oxford University Press.

Greenleaf, S. S., and C. Kremen. 2006. Wild bee species increase tomato production and respond differently to surrounding land use in Northern California. Biological Conservation 133:81-87.

Kareiva, P., H. Tallis, T. H. Ricketts, G. C. Daily, and S. Polasky, editors. 2011. Natural capital: theory and practice of mapping ecosystem services. Oxford University Press, Oxford, UK.

Kennedy, C. M., et al. 2013. A global quantitative synthesis of local and landscape effects on wild bee pollinators in agroecosystems. Ecology Letters. http://dx.doi.org/10.1111/ ele. 12082

Klein, A., I. Steffan-Dewenter, and T. Tscharntke. 2003. Fruit set of highland coffee increases with the diversity of pollinating bees. Proceedings of the Royal Society B 270:955-961.

Klein, A. M., B. E. Vaissiere, J. H. Cane, I. Steffan-Dewenter, S. A. Cunningham, C. Kremen, and T. Tscharntke. 2007. Importance of pollinators in changing landscapes for world crops. Proceedings of the Royal Society B 274:303-313.

Kremen, C. 2005. Managing ecosystem services: What do we need to know about their ecology? Ecology Letters 8:468479 .

Kremen, C., N. M. Williams, and R. W. Thorp. 2002. Crop pollination from native bees at risk from agricultural intensification. Proceedings of the National Academy of Sciences USA 99:16812-16816.

Lonsdorf, E., C. Kremen, T. Ricketts, R. Winfree, N. Williams, and S. Greenleaf. 2009. Modelling pollination services across agricultural landscapes. Annals of Botany 103:1589-1600.

Lonsdorf, E., T. H. Ricketts, C. M. Kremen, N. M. Williams, and S. Greenleaf. 2011. Crop pollination services. Pages 168187 in P. Kareiva, H. Tallis, T. H. Ricketts, G. C. Daily, and S. Polasky, editors. Natural capital: theory and practice of mapping ecosystem services. Oxford University Press, Oxford, UK.

Margules, C. R., and R. L. Pressey. 2000. Systematic conservation planning. Nature 405:243-253.

Millennium Ecosystem Assessment. 2005. Ecosystems and human well-being: synthesis. Island Press, Washington, D.C., USA.

Murdoch, W., S. Polasky, K. A. Wilson, H. P. Possingham, P. Kareiva, and R. Shaw. 2007. Maximizing return on investment in conservation. Biological Conservation 139:375-388.

Naidoo, R., A. Balmford, R. Costanza, B. Fisher, R. E. Green, B. Lehner, T. R. Malcolm, and T. H. Ricketts. 2008. Global mapping of ecosystem services and conservation priorities. Proceedings of the National Academy of Sciences USA 105:9495-9500.

Naidoo, R., A. Balmford, P. J. Ferraro, S. Polasky, T. H. Ricketts, and M. Rouget. 2006. Integrating economic costs into conservation planning. Trends in Ecology and Evolution 21:681-687.

Naidoo, R., and T. H. Ricketts. 2006. Mapping the economic costs and benefits of conservation. PLoS Biology 4:21532164.

Nelson, E., et al. 2009. Modeling multiple ecosystem services, biodiversity conservation, commodity production, and trade- 
offs at landscape scales. Frontiers in Ecology and the Environment 7:4-11.

Ostrom, E. 2000. Collective action and the evolution of social norms. Journal of Economic Perspectives 14:137-158.

Pfaff, A., J. A. Robalino, and G. A. Sanchez-Azofeifa. 2008. Payments for Environmental Services: Empirical analysis for Costa Rica. Working paper. Terry Sanford Institute of Public Policy, Duke University, Durham, North Carolina, USA.

Polasky, S., G. Calderone, K. E. Duarte, J. Goldstein, N. Hannahs, T. H. Ricketts, and H. Tallis. 2011. Putting ecosystem services to work: conservation, management, and trade-offs. Pages 249-263 in P. Kareiva, H. Tallis, T. H. Ricketts, G. C. Daily, and S. Polasky, editors. Natural capital: theory and practice of mapping ecosystem services. Oxford University Press, Oxford, UK.

Priess, J. A., M. Mimler, A. M. Klein, S. Schwarze, T. Tscharntke, and I. Steffan-Dewenter. 2007. Linking deforestation scenarios to pollination services and economic returns in coffee agroforestry systems. Ecological Applications 17:407-417.

Richardson, D. M., B. W. vanWilgen, S. I. Higgins, T. H. TrinderSmith, R. M. Cowling, and D. H. McKell. 1996. Current and future threats to plant biodiversity on the Cape Peninsula, South Africa. Biodiversity and Conservation 5:607-647.

Ricketts, T. H. 2004. Tropical forest fragments enhance pollinator activity in nearby coffee crops. Conservation Biology 18:1262-1271.

Ricketts, T. H., G. C. Daily, P. R. Ehrlich, and C. D. Michener. 2004. Economic value of tropical forest to coffee production. Proceedings of the National Academy of Sciences USA 101:12579-12582.
Ricketts, T. H., et al. 2008. Landscape effects on crop pollination services: are there general patterns? Ecology Letters 11:499-515.

Salzman, J. 2005. Creating markets for ecosystem services: notes from the field. New York University Law Review 80:870-961.

Steffan-Dewenter, I., S. G. Potts, and L. Packer. 2005. Pollinator diversity and crop pollination services are at risk. Trends in Ecology and Evolution 20:651-652.

Tallis, H., P. Kareiva, M. Marvier, and A. Chang. 2008. An ecosystem services framework to support both practical conservation and economic development. Proceedings of the National Academy of Sciences USA 105:9457-9464.

Turner, R. K., S. Morse-Jones, and B. Fisher. 2010. Ecosystem valuation: a sequential decision support system and quality assessment issues. Annals of the New York Academy of Sciences 1185:79-101.

Turner, R. K., J. Paavola, P. Cooper, S. Farber, V. Jessamy, and S. Georgiou. 2003. Valuing nature: lessons learned and future research directions. Ecological Economics 46:493-510.

Turner, R. K., D. Pearce, and I. Bateman. 1993. Environmental economics: an elementary introduction. Johns Hopkins University Press, Baltimore, Maryland, USA.

Wilson, K. A., M. F. McBride, M. Bode, and H. P. Possingham. 2006. Prioritizing global conservation efforts. Nature 440:337-340.

Wunder, S., S. Engel, and S. Pagiola. 2008. Taking stock: a comparative analysis of payments for environmental services programs in developed and developing countries. Ecological Economics 65:834-852.

\section{Supplemental Material}

\section{Appendix}

Detailed description of generic model and parameter tables (Ecological Archives A023-058-A1). 